\title{
Influence of crack arresting rib on the fracture characteristic of integral wing-spar
}

\author{
Junjie Yin ${ }^{\mathrm{a}}$, Shulin $\mathrm{Li}^{\mathrm{b}}$, Fei Chang ${ }^{\mathrm{c}}$ and Xiaopeng Shi ${ }^{\mathrm{d}}$ \\ Aeronautics and Astronautics Engineering College, Airforce Engineering University, Xi'an 7100380, \\ China \\ a330356322@qq.com, ${ }^{b}$ I.s.lin2008@163.com, changefly@gmail.com, ${ }^{d}$ sxp2005501@126.com
}

Keywords: Crack arresting rib, Integral wing- spar, Fracture characteristic, Stress intensity factor.

\begin{abstract}
Focus on the problem that fracture characteristic of integral structure is worse than composite structure, this paper studied the influence of anti-crack rib design parameters on the fracture characteristic of integral wing-spar through calculating the stress intensity factor and constructing support vector machine agent model. Results indicated that crack arresting rib could enhance the fracture characteristic of integral wing-spar well. When crack extended to crack arresting rib, residual strength of integral wing-spar will enhance for about 36\%, crack growth life enhance about $13.5 \%$; the best location of crack arresting rib is at $1 / 3$ the height of wing-spar. Conclusions gained could provide reference for damage tolerance design of integral wing-spar.
\end{abstract}

\section{Introduction}

Recent years, integral structures are widely used in the territory of aerospace engineering for its simple process technology, lighter weight when bearing same stress, fewer potential crack origin and stress concentrate position ${ }^{[1]}$. However, lacking "natural” anti-crack component like stringer and rivet hole, seriously influenced the fracture characteristic of integral structure. NASA had done some experiments on fatigue crack growth between integral structure and composite structure ${ }^{[2-3]}$, their results indicated that crack growth rate of composite structure is slower than that of integral structure when crack cross through the skin. Therefore, how to improve the fracture characteristic of integral structure becomes a research hotspot among investigators.

At present, researchers home or abroad had already done some experiments and simulations to study the fracture characteristic of integral structure ${ }^{[4-8]}$. Their study achievements provided some guidance for integral structure design. For example with integral wing-spar, in order to improve its fracture characteristic, we can locate crack arresting rib on the webs of wing-spar.

The investigation objective of this paper is crack arresting rib of integral wing-spar. Through calculating stress intensity factor (SIF) on crack tip, and combing support vector machine (SVM) agent model, we analyzed the specific influence of anti-crack rib design parameters on the fracture characteristic of integral wing-spar.

\section{Integral wing-spar}

Aircraft integral wing-spar consists of upper and lower flange, webs and crack arresting rib, sectional sketch map and parameters of it are shown in Fig. 1. The value of sectional parameters is shown in Table 1. Length of the spar is $5000 \mathrm{~mm}$. In order to analyze the influence of crack arresting rib design parameters to the fracture characteristic of integral wing-spar, the varied range of crack arresting rib design parameters is given in Table 2.

We put forward the following supposes in our research: initial crack is located in the middle of the spar, the lower flange is complete break and crack extends $25 \mathrm{~mm}$ on the webs; according to the design requirement, when the crack extends to anti-crack rib, we regard it as the critical crack; crack growth trajectory is straight line. The sketch maps of initial crack and critical crack are shown in Fig. 2. 
Material of the wing-spar is 7050-T7451, elastic modulus E=70GPa, material Poisson's ratio $\mathrm{v}=0.33$, ultimate strength $\sigma_{b}=511 \mathrm{MPa}$, material fracture toughness $K_{\mathrm{IC}}=72 \mathrm{MPa} \sqrt{\mathrm{m}}$.

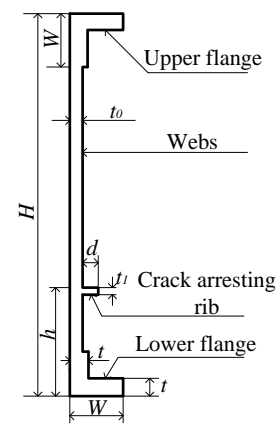

Fig. 1 Sectional sketch map of integral wing-spar
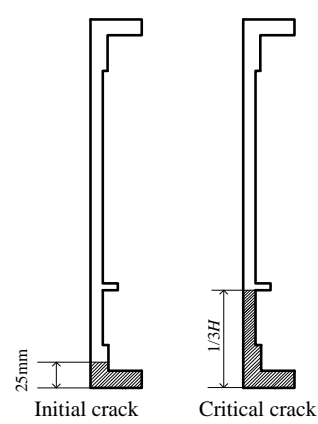

Table.1 Specific parameters

\begin{tabular}{ccccccc}
\hline $\begin{array}{c}\text { Spar height } \\
H / \mathrm{mm}\end{array}$ & $\begin{array}{c}\text { Webs } \\
\text { thickness } \\
t_{0} / \mathrm{mm}\end{array}$ & $\begin{array}{c}\text { Flange } \\
\text { width } \\
W / \mathrm{mm}\end{array}$ & $\begin{array}{c}\text { Flange } \\
\text { thickness } \\
t / \mathrm{mm}\end{array}$ & $\begin{array}{c}\text { Crack } \\
\text { arresting rib } \\
\text { location } \\
h / \mathrm{mm}\end{array}$ & $\begin{array}{c}\text { Crack } \\
\text { arresting rib } \\
\text { thickness } \\
t_{1} / \mathrm{mm}\end{array}$ & $\begin{array}{c}\text { Crack arresting } \\
\text { rib height } \\
b / \mathrm{mm}\end{array}$ \\
\hline 1000 & 6.25 & 90 & 9.5 & $H / 3$ & $W / 9$ & $W / 3$ \\
\hline
\end{tabular}

Table.2 Crack arresting rib parameters

\begin{tabular}{cccc}
\hline Anti-crack parameters & $h / \mathrm{mm}$ & $d / \mathrm{mm}$ & $t_{1} / \mathrm{mm}$ \\
\hline Range scale & $260 \sim 440$ & $20 \sim 40$ & $6 \sim 12$ \\
\hline
\end{tabular}

\section{Fracture characteristic calculated method}

\section{Stress intensity factor.}

Usually, we can calculate SIF by consulting some formula or figure directly to structure with simple shape. However, as a complex engineering structure, there exist no references for integral wing-spar to calculate SIF.

Accompany with the development of finite element code such as ANSYS, we can calculate SIF based on the relationship between SIF and normal displacement in crack surface, this method is called direct displacement method. The relationship is represented by ${ }^{[7]}$

$$
\mathrm{V}^{\prime}=\frac{(1+v) K_{1}}{2 E} \sqrt{\frac{r}{2 \pi}}\left[(2 s+1) \sin \frac{\phi}{2}-\sin \frac{3 \phi}{2}\right]
$$

Where $s=(3-v) /(1+v)$ (plane stress), $s=3-4 v$ (plane strain), $v$ is material Poisson's ratio, $\phi$ is intersectional angle between crack surface and crack centre line.

In this paper, we chose ANSYS to calculate SIF. The parametric model of integral wing-spar was constructed through the APDL language in ANSYS software. According to the characteristic of integral wing-spar, we chose shell element as the modeling element. In order to eliminate the singularity, crack tip element type was set as shell 93.

In the process of exerting boundary, one side of the wing-spar was fixed, the other side was exerted $30 \mathrm{kN}$ concentrate force.

At the stage of after-deal, we use the command "KCALC" to calculate SIF.

\section{Residual strength.}

The bearing capacity of structure with crack is called residual strength. Its expression can be represented by

$$
\sigma_{\text {res }}=\frac{\mathrm{K}_{\mathrm{IC}}}{\beta \sqrt{\pi a}}
$$


Where KIC is material fracture toughness, if material is fixed, KIC is a constant; a is half crack length, $\beta$ is compensation factor.

In fracture mechanics, the common expression of SIF is represented by ${ }^{[9]}$

$$
\mathrm{K}_{\mathrm{I}}=\beta \sigma \sqrt{\pi a}
$$

Where $\sigma$ is realistic exert stress.

Combining Eq. (2) and Eq. (3), residual strength also can be represented by

$$
\sigma_{\text {res }}=\frac{\mathrm{K}_{\mathrm{IC}}}{\mathrm{K}_{\mathrm{I}}} \sigma
$$

Known from the Eq. (4), calculating SIF is a key procedure for us if we want to compute residual strength.

\section{Crack growth life.}

Crack growth life represents the time when a crack change from initial crack a0 to critical crack ac. According to the curve between SIF and crack length a, we can calculate crack growth life based on crack growth rate equations. In this paper, we chose Walker equation to calculate crack growth life, it is presented by ${ }^{[9]}$

$$
\frac{d a}{d N}=C\left[(1-R)^{m} K_{\max }\right]^{n}
$$

Through some simple changes, crack growth life $\mathrm{N}$ is represented by

$$
N=\int_{a_{0}}^{a_{c}} \frac{1}{C\left[(1-R)^{m} K_{\max }\right]^{n}} d a
$$

Where $\mathrm{N}$ is crack growth life; a0 is initial crack length; ac is critical crack length; $\mathrm{C}, \mathrm{m}, \mathrm{n}$ are material constant; $\mathrm{R}$ is stress ratio; Kmax is maximum SIF.

\section{Construct SIF agent model by SVM}

Agent model ${ }^{[10]}$ is a mathematical model which has similar result with physics experiment or numerical simulation. Through agent model, we can forecast the response for arbitrary unknown point. At present, we can construct agent model by the method of polynomial regression model, Kriging model, neural network model and SVM model ${ }^{[11-14]}$. Known from references [15] and [16], agent model constructed by theory of SVM has higher accuracy if the specimen scale is small, the forecast value can fit the true value well.

In this paper, SIF agent model was directly constructed by LIBSVM ${ }^{[17]}$ toolbox which was installed in MATLAB software. The flow chart of constructing agent model is shown in Fig. 3.

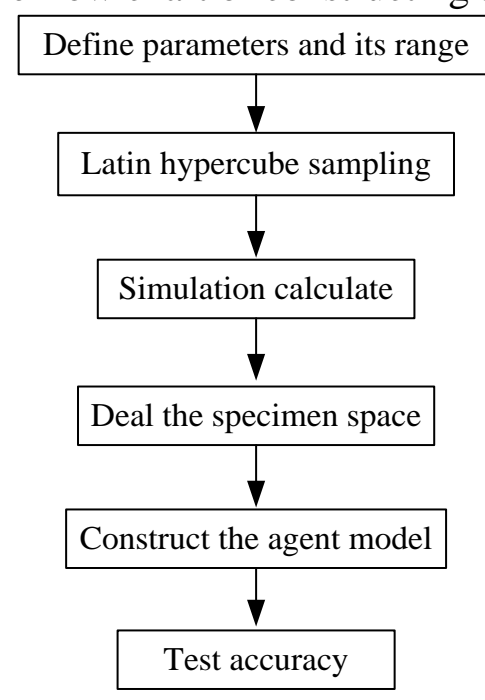

Fig. 3 Flow chart of agent model 


\section{Results and analysis}

\section{Within or without crack arresting rib.}

We took the parameters' value in Tab. 1 into finite element model constructed in section 2.1 and calculate SIF under different crack length. Through modifying the finite element model, SIF without crack arresting rib was also calculated as well. Change regular of SIF between within and without crack arresting rib was compared. The change curve is shown in Fig. 4.

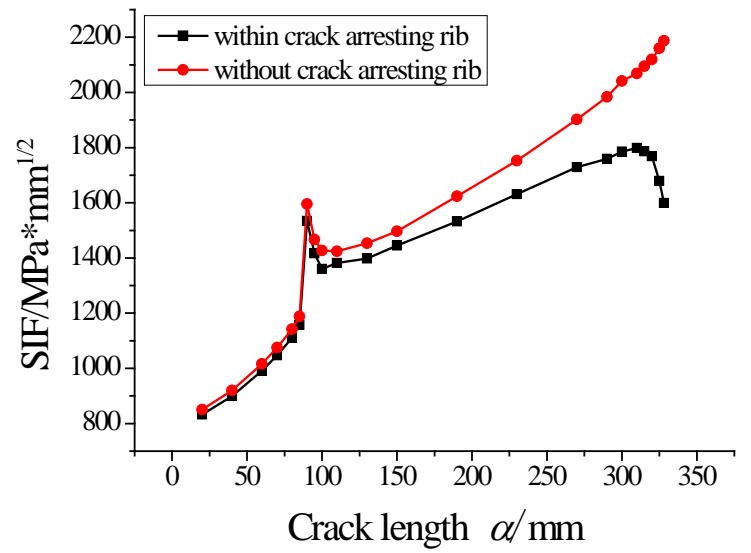

Fig. 4 SIF comparison between within and without crack arresting rib

Fig. 4 shows that, when crack length changes from $25 \mathrm{~mm}$ to $100 \mathrm{~mm}$, crack arresting rib has few influence on SIF, within and without crack arresting rib has same result; when crack length is longer than $100 \mathrm{~mm}$, the influence of crack arresting rib on SIF is gradually enhanced, SIF with crack arresting rib is smaller than without, and the D-value becomes larger with the extending of crack; when crack extend to $25 \mathrm{~mm}$ under the crack arresting rib, change trend of SIF without crack arresting rib is still increasing, but that of SIF within crack arresting rib decreases obviously.

In conclude, crack arresting rib can enhance the fracture characteristic of integral wing-spar, and this function becomes more and more obvious with the extending of crack. Through calculation, crack extended to anti-crack rib, residual strength of integral wing-spar enhanced about $36 \%$, and the crack growth life enhanced about $13.5 \%$.

\section{Crack arresting rib location.}

Parameters except $\mathrm{h}$ were fixed, by changing the crack arresting rib location parameter $\mathrm{h}$ based on Table 2, we calculated SIF when crack extends from initial crack to critical crack. Calculating result curves are shown in Fig. 5.

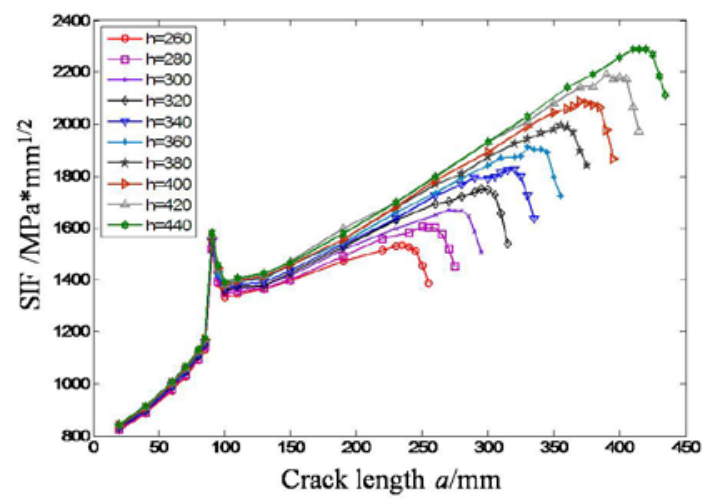

Fig. 5 SIF with different crack arresting rib location

Known from the Fig. 5, every a-SIF curve has its SIF maximum value at different crack arresting rib location h, and the corresponding crack length is about H/3-25mm, that is to say, the crack has already extended to $25 \mathrm{~mm}$ under the anti-crack rib. According to Eq. (4), when crack length is fixed, the relationship between residual strength and SIF is inverse ratio. Therefore, the integral wing-spar exist a minimum residual strength in the extended process of crack, the relationship between minimum residual strength under different crack arresting rib location and parameter $\mathrm{h}$ is shown in Fig. 6. 
Known from the Fig. 6, minimum residual strength decreases accompany with the increase of h. Through calculating, if anti-crack rib location enhanced 6\%, minimum residual strength decreases $4 \%$.

We carried out Gauss Fitting to every curve draw in Fig. 5, gained the expression between crack length a and SIF, and then put it into Eq. (6) to calculated crack growth life under different crack arresting rib location, the relationship between crack growth life and parameter h is shown in Fig. 7.

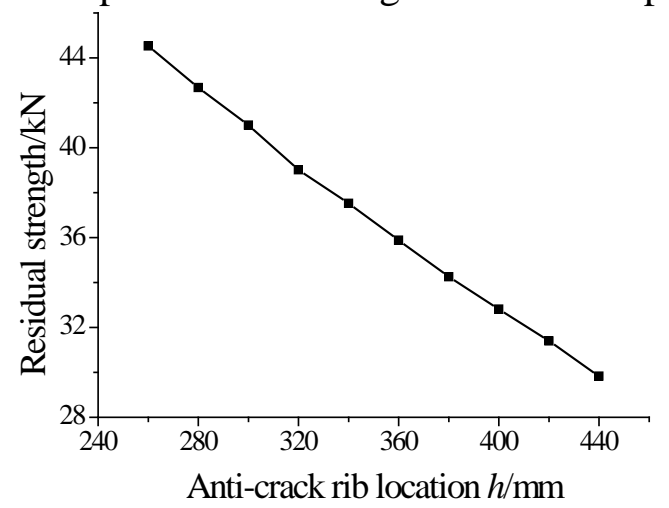

Fig. 6 Residual strength and anti-crack rib location

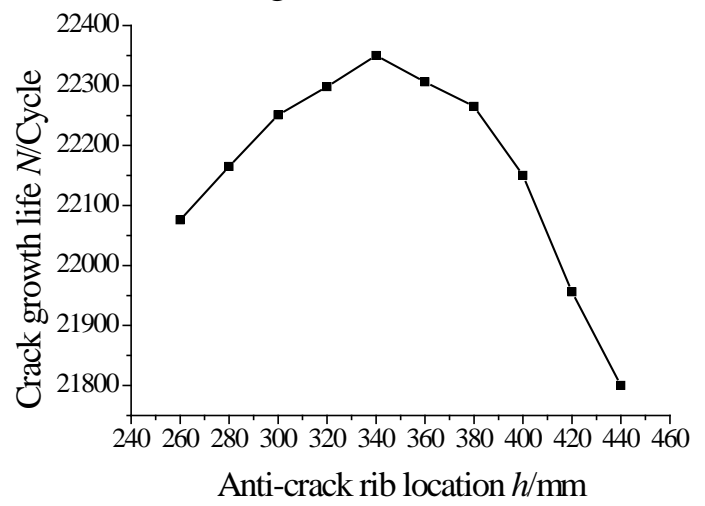

Fig. 7 Crack growth life and anti-crack rib location

Known from Fig. 7, when parameter h is changing from $260 \mathrm{~mm}$ to $340 \mathrm{~mm}$, crack growth life increases accompany with the increase of $h$; when parameter $h$ is changing from $340 \mathrm{~mm}$ to $440 \mathrm{~mm}$, crack growth life is decreasing.

If the parameter $\mathrm{h}$ increases, integral interval of Eq. (6) will became larger, however, the value of SIF is still larger at the same crack length known from the Fig. 5, and the value of integrand will decreasing. Therefore, when parameter $h$ is bigger than some detail value, crack growth life is decreasing.

Combine the Fig. 6 and Fig. 7, crack arresting rib location was not the higher the better, took both the residual strength and crack growth life into consideration, the best value of crack arresting rib location was about 340mm, 1/3 the height of wing-spar $\mathrm{H}$.

\section{Crack arresting rib width and thickness.}

Here we used the method of Latin Hypercube Sampling to extract 60 groups samples for crack arresting rib width and thickness parameters. Then we took these samples into finite element model, in which crack arresting rib location $h=1 / 3 \mathrm{H}$. Calculated SIF under the crack length was $1 / 3 \mathrm{H}-25 \mathrm{~mm}$. Then we constructed the SIF agent model through the theory of SVM by the toolbox of LIBSVM in MATLAB. In order to test the accuracy of the SIF agent model, we extracted another 5 groups samples, calculated their SIF by the method of both agent model and finite element parameterize model, the forecasted value and calculated value are shown in Table. 3. By contrasting the forecasted value and calculated value, we can find the error is about $0.05 \%$, so the agent model has high accuracy. 
Table. 3 Data comparison

\begin{tabular}{ccc}
\hline Calculate value $/ \mathrm{Mpa}^{*} \mathrm{~mm}^{1 / 2}$ & Forecast valve $/ \mathrm{Mpa}^{*} \mathrm{~mm}^{1 / 2}$ & error(\%) \\
\hline 1869.4 & 1870.516 & 0.0597 \\
1860.0 & 1860.640 & 0.0347 \\
1793.5 & 1793.418 & -0.0050 \\
1779.9 & 1779.166 & -0.0417 \\
1727.5 & 1727.606 & 0.0067 \\
\hline
\end{tabular}

Through the SIF agent model, we can forecast the SIF under arbitrary crack arresting rib width and thickness combination in full varied range of parameters' value. The forecast value is shown in Fig. 8.

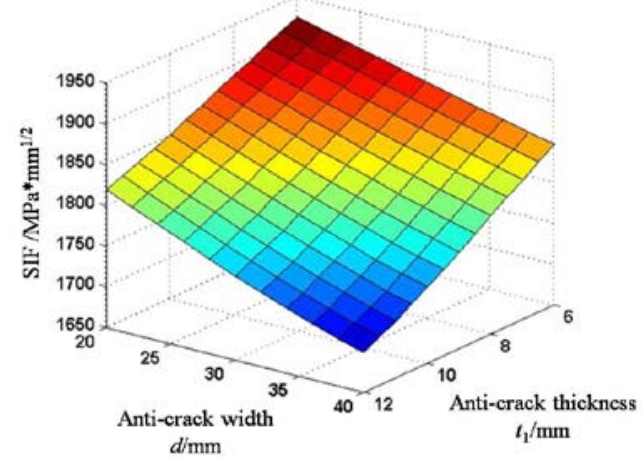

Fig. 8 Anti-crack rib width and thickness and SIF

Fig. 8 indicates that, SIF has the same value if the crack arresting rib sectional area is the same. When crack arresting rib sectional area increases, SIF decreases, and residual strength enhances.

When crack arresting rib sectional area is fixed, we calculated the SIF under different width and thickness ratio, the change trend between SIF and width and thickness ratio is shown in Fig. 9.

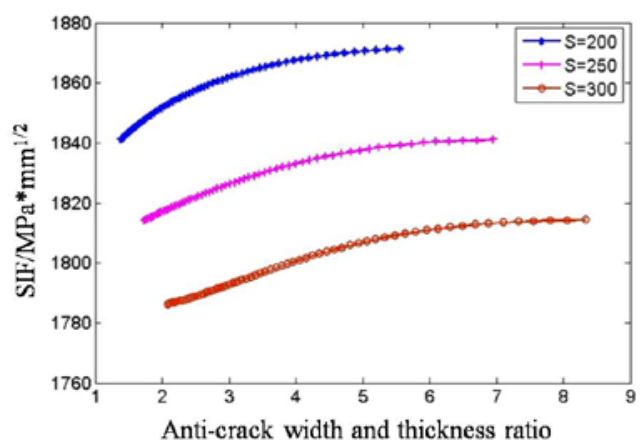

Fig. 9 Thickness ratio and SIF

As is shown in Fig. 9, when the crack arresting rib sectional area is fixed, SIF increases accompany with the increase of anti-crack rib width and thickness ratio, eventually, SIF reaches a constant value. When the crack arresting rib sectional area increases, width and thickness ratio has less influence on SIF.

\section{Conclusions}

We can draw following conclusions through analyzing the influence of crack arresting rib design parameters on the fracture characteristic of integral wing-spar:

(1) Crack arresting rib could enhance the fracture characteristic of integral wing-spar well, when the crack extend to crack arresting rib, compared with none crack arresting rib, the residual strength of integral wing-spar enhances about 36\%, and the crack growth life enhances for about $13.5 \%$;

(2) Crack arresting rib location parameter has great influence on the fracture characteristic of integral wing-spar, take both the residual strength and crack growth life into considerate, the best location of crack arresting rib should be at $1 / 3$ of the spar height; 
(3) Sectional area of crack arresting rib influenced the value of SIF directly. When the crack length is fixed, SIF decreases with the increase of sectional area; Crack arresting rib width and thickness ratio has few influences on the characteristic of integral wing-spar.

\section{References}

[1] Yin Junjie, Chang Fei, Li Shulin. Analysis of Parameter Sensitivity to Damage Tolerance Design of Overall Spar Based on Sobol Method[J].Journal of Air force engineering university, 2013,14(6): 9-12.(in Chinese)

[2] J.Munroe, K.Wilkins, and M.Gruber. Integral Airframe Structures (IAS)—Validated Feasibility Study of Integrally Stiffened Metalli Fuselage Panel for Reducing Manufacturing. NASA/CR-2000-209337.

[3] B.R.Seshadri, M.A.James, W.M.Jolmston, Jr. And R.D. Young Recent Development in the Analysis of Monolithic Structures at NASA Langley. NASA/CR-2000-209343.

[4] Yin Zhiping, Huang Qiqing, Fu Xiangjiong. Damage tolerance behavior of plates with Variable thickness [J].Chinese Journal of Applied Mechanics, 2005, 22(4):665-668. (in Chinese)

[5] Wang Shengnan, Zhang Nina, Qin Jianbo. Exploring Engineering Significance of Turning of Longitudinal Crack in Integral Airframe Structure [J].Journal of Northwestern Polytechnical University, 2007, 25(4):472-477. (in Chinese)

[6] Zhai Xinkang, Huang Qiqing, Yin Zhiping. Crack Propagation Experiment and Analysis of Wing Spar Integral Structure [J]. Journal of Mechanical Strength, 2007, 29(6): 987-991. (in Chinese)

[7] Huang Qiqing, LIU Jinzheng, YIN Zhiping. Fracture Characteristics Analysis Method and Study of Wing-Spar Integral Structure [J].Aeronautical Computing Technique, 2006,36(2): 114-119. (in Chinese)

[8] Zhai Xinkang, Huang Qiqing, Yin Zhiping et al. Analysis and Research of Fracture Characteristics for Wing Spar Integral Structures [J]. Aeronautical Computing Technique, 2007, 37(4):71-74. (in Chinese)

[9] Chen Chuanyao. Fatigue and Fracture[M]. Wuhan: Huazhong University of Science and Technology Press[M], 2001,95-132. (in Chinese)

[10] Giunta A A. Aircraft multidisciplinary design optimization using design of experiments theory and response surface modeling methods [D]. PhD Dissertation, Virginia Polytechnic Institute, 1997.

[11]Knill D L, Giunta A A, Baker C A. Response surface models combining linear and euler aerodynamics for supersonic transport design [J].J Aircraft, 1999, 36(1): 75-86.

[12] Levin N D D, Rippa S. Numerical procedures for surface fitting of scattered data by radial basis functions[J].SIAM Journal of Scientific and Statistical Computing, 1986,7(2): 639-659.

[13]Liu Jike, Zhaowei. Response Surface Method for Reliability Computation Based on Support Vector Regression [J]. Journal of Zhong Shan University (Natural Sciences), 2008, 47(1): 1-4. (in Chinese)

[14] Jin R, Chen W, Simpson T W. Comparative studies of metamodeling techniques under multiple modeling criteria [J]. Structural and Multidisciplinary Optimization, 2001, 23(1):456-476.

[15] Tang Chunxi, Jin Weiliang, Chen Jin.Importance Sampling Method Based on SVM[J].Journal of Yangtze River Scientific Research Institute, 2007,24(6):62-65. (in Chinese)

[16]He Zhen, Cui Qingan. A Study on the Small Sample Response Surface Methodology Based on SVM[J]. Industrial Engineering Journal, 2006,9(5):5-9.(in Chinese)

[17]Chih-Chang, Chih-Jen Lin. LIBSVM: a Library for Support Vector Machine[DB/OL], http://www.csie.ntu.tw/ cjlin/libsvm, 2001. 